\title{
Solvothermal syntheses and structural characterization of a series of metal-hydroxycarboxylate coordination polymers
}

\author{
Jian-Qiang Liu ${ }^{\text {a }}$, Yao-Yu Wang ${ }^{\mathrm{a}, *}$, Lu-Fang Ma ${ }^{\mathrm{a}}$, Wei-Hong Zhang ${ }^{\mathrm{a}}$, Xi-Rui Zeng ${ }^{\mathrm{b}}$, \\ Qi-Zhen Shi ${ }^{\mathrm{a}}$, Shie-Ming Peng ${ }^{\mathrm{c}}$ \\ ${ }^{a}$ Department of Chemistry and Shaanxi Key Laboratory of Physico-inorganic Chemistry, Northwest University, Xi'an 710069, PR China \\ ${ }^{\mathrm{b}}$ Department of Chemistry, JingGangShan College, Ji'an 343009, PR China \\ ${ }^{\mathrm{c}}$ Department of Chemistry, National Taiwan University, Taipei, Taiwan
}

Received 2 September 2007; received in revised form 28 November 2007; accepted 28 November 2007

Available online 14 December 2007

\begin{abstract}
The combination of transition metal ions with mixed ligands resulted in the formation of three new coordination polymers, $\left\{\left[\mathrm{Co}\left(\mathrm{C}_{4} \mathrm{H}_{4} \mathrm{O}_{5}\right)(\text { bpe })\left(\mathrm{H}_{2} \mathrm{O}\right)_{2}\right] \cdot(0.5 \mathrm{bpe})\left(\mathrm{H}_{2} \mathrm{O}\right)\right\}_{n}(\mathbf{1}),\left\{\left[\mathrm{Cu}\left(\mathrm{C}_{4} \mathrm{H}_{4} \mathrm{O}_{6}\right)(\text { bipy })\right] \cdot 5 \mathrm{H}_{2} \mathrm{O}\right\}_{n}(2)$ and $\left\{\left[\mathrm{Cu}\left(\mathrm{C}_{4} \mathrm{H}_{4} \mathrm{O}_{5}\right)(\mathrm{bpa})\right] \cdot 2.5 \mathrm{H}_{2} \mathrm{O}\right\}_{n}(\mathbf{3})\left(\mathrm{C}_{4} \mathrm{H}_{4} \mathrm{O}_{5}^{2-}\right.$ $=$ malate dianion, $\mathrm{C}_{4} \mathrm{H}_{4} \mathrm{O}_{6}^{2-}=$ tartrate dianion, bpe $=1$,2-bis(4-pyridyl)ethene, bipy = 2,2'-bipyridine, bpa $=1$,2-bis(4-pyridyl)ethane), which were prepared under solvothermal conditions and characterized by single-crystal X-ray diffraction. 1 and $\mathbf{2}$ feature 1D chain structures. Interestingly, each pair of chains recognizes each other through aromatic $\pi-\pi$ stacking interactions, generating a zipper-like double-stranded chain in $\mathbf{2}$. Compound 3 shows $2 \mathrm{D} 6^{3}$ topology framework with a rectangle-like grid.
\end{abstract}

(C) 2007 Elsevier B.V. All rights reserved.

Keywords: Hydroxycarboxylate ligands; Crystal structures; Solvothermal syntheses; Magnetic behavior

\section{Introduction}

Crystal engineering of metal-organic networks via selfassembly of metal ions and multi-functional ligands has attracted considerable attention because of the structural diversity presented in such compounds which in turn facilitates systematic evaluation of structure property relationships [1-9]. Carboxylate complexes have been investigated over the past years due to their interesting coordination chemistry, allowing for unusual structural features and leading to various physical and chemical properties and practical applications in some fields such as dyes, extractants, drug, pesticides and catalysts [10-12]. The aromatic multi-carboxylate ligands, such as benzenedi-, benzenetri-, benzenetetra- and nitrogen-containing heterocyclic dicarboxylates, have been extensively introduced in the prepara-

\footnotetext{
${ }^{*}$ Corresponding author. Tel./fax: +86 02988303798.

E-mail address: wyaoyu@nwu.edu.cn (Y.-Y. Wang).
}

tions of metal-organic supramolecular open frameworks [13-17]. However, the hydroxyl polycarboxylates (HPCs), such as malate, citrate and tartrate, have been less studied as building blocks in the construction of metal-organic frameworks $[18,19]$. We believe that the application of these bridging ligands with conformation freedoms is beneficial to the adjustment of structures and properties, although the structural control of the product is difficult. $\mathrm{Xu}$ et al. have synthesized successfully some coordination polymers $[20,21]$. 3D interpenetrating topology networks and supramolecular polymers with malate are reported recently by our group, which is a good example of $1 \mathrm{D}$ magnetic systems with various magnetic exchange interactions $[22,23]$.

Herein, we extend these studies to explore the interaction of two types of hydroxycarboxylate ligands with transition-metal ions, and $\mathrm{N}$-donor ligands to pursue the aim of designing new compounds exhibiting various architectures and magnetic ordering. This paper reports the syntheses and characterization of three new coordination polymers, 
namely $\left\{\left[\mathrm{Co}\left(\mathrm{C}_{4} \mathrm{H}_{4} \mathrm{O}_{5}\right)(\text { bpe })\left(\mathrm{H}_{2} \mathrm{O}\right)_{2}\right] \cdot(0.5 \mathrm{bpe})\left(\mathrm{H}_{2} \mathrm{O}\right)\right\}_{n} \quad$ (1), $\left\{\left[\mathrm{Cu}\left(\mathrm{C}_{4} \mathrm{H}_{4} \mathrm{O}_{6}\right)(\text { bipy) }) \cdot 5 \mathrm{H}_{2} \mathrm{O}\right\}_{n}\right.$ (2) and $\left\{\left[\mathrm{Cu}\left(\mathrm{C}_{4} \mathrm{H}_{4} \mathrm{O}_{5}\right)(\mathrm{b}-\right.\right.$ pa) $\left.] \cdot 2.5 \mathrm{H}_{2} \mathrm{O}\right\}_{n}(3)\left(\mathrm{C}_{4} \mathrm{H}_{4} \mathrm{O}_{5}^{2 z}=\right.$ malate dianion, $\mathrm{C}_{4} \mathrm{H}_{4} \mathrm{O}_{6}^{2-}$ $=$ tartrate dianion, bpe $=1,2$-bis(4-pyridyl)ethene, bipy $=$ 2,2'-bipyridine, $\quad$ bpa $=1,2$-bis(4-pyridyl)ethane). Single crystal X-ray analyses show that functional ligands play an important role in the affecting the final structural motifs. In 1, with malate only acting as appending fashion and bpe acting as ditopic subunit, the self-assembly results in a 1D chain, while in 3, with malate acting as tetratopic subunit and bpa acting as ditopic subunit, an appealing 2D $6^{3}$ topological framework is obtained. In 2, with bipy acting as terminal ligand, the self-assembly results in a zipper-like double-stranded chain. To the best of our knowledge, these are three new, previously unreported types of structural motifs.

\section{Experimental}

\subsection{General procedures}

All reagents were purchased from commercial sources and used as received. IR spectra were recorded with a Perkin-Elmer Spectrum one spectrometer in the region 4000$400 \mathrm{~cm}^{-1}$ using $\mathrm{KBr}$ pellets. The luminescent spectra of the solid samples were acquired at ambient temperature by using a JOBIN YVON/HORIBA SPEX Fluorolog t3 system (slit: $0.2 \mathrm{~nm}$ ). TG analyses were carried out with a Metter-Toledo TA 50 in dry dinitrogen $\left(60 \mathrm{~mL} \mathrm{~min}^{-1}\right)$ at a heating rate of $5^{\circ} \mathrm{C} \mathrm{min}-1$. X-ray power diffraction (XRPD) data were recorded on a Rigaku RU200 diffractometer at $60 \mathrm{kV}, \quad 300 \mathrm{~mA}$ for $\mathrm{Cu} \mathrm{K} \alpha$ radiation $(\lambda=1.5406 \AA)$, with a scan speed of $2^{\circ} / \mathrm{min}$ and a step size of $0.04^{\circ}$ in $2 \theta$. The magnetic susceptibility was obtained on crystalline sample using a Quantum Design MIPMS SQUID magnetometer. The experiment susceptibility was corrected for the sample holder and the diamagnetism contribution estimated from Pascal's constant.

\subsubsection{Synthesis of $\left\{\left[\mathrm{Co}\left(\mathrm{C}_{4} \mathrm{H}_{4} \mathrm{O}_{5}\right)(\right.\right.$ bpe $\left.)\left(\mathrm{H}_{2} \mathrm{O}\right)_{2}\right]$. \\ (0.5 bpe) $\left.\left(\mathrm{H}_{2} \mathrm{O}\right)\right\}_{n}(1)$}

A mixture of malic acid $(0.210 \mathrm{~g}, 1.55 \mathrm{mmol}), \mathrm{NaOH}$ $(0.080 \mathrm{~g}, 2 \mathrm{mmol}), \mathrm{CoCl}_{2} \cdot 6 \mathrm{H}_{2} \mathrm{O}(0.152 \mathrm{~g}, 0.073 \mathrm{mmol})$, bpe $(0.028 \mathrm{~g}, 0.015 \mathrm{mmol}), \mathrm{CH}_{3} \mathrm{OH}(4 \mathrm{~mL})$ and distilled water $(12 \mathrm{~mL})$ was stirred for $5 \mathrm{~min}$ in air, then transferred and sealed in a $25 \mathrm{~mL}$ Teflon-lined autoclave, which was heated at $140{ }^{\circ} \mathrm{C}$ for $72 \mathrm{~h}$. The autoclave was cooled over a period of $12 \mathrm{~h}$ at a rate of $5^{\circ} \mathrm{C} \mathrm{h}^{-1}$, to yield a very fine pink crystalline product 1 in $50 \%$ yield. Anal. Calc. for $\mathrm{C}_{22} \mathrm{H}_{24} \mathrm{CoN}_{3} \mathrm{O}_{8}$ (1): C, 51.35; H, 4.04; N, 7.49. Found: C, $51.88 ; \mathrm{H}, 4.21 ; \mathrm{N}, 7.33 \%$. IR $\left(\mathrm{KBr}, \mathrm{cm}^{-1}\right)$ for $1: 3462(\mathrm{~m})$, 3102(m), 1692(vs), 1597(m), 1405(vs), 1273(vs), 1182(vs), 1064(m), 882(vs), 608(m),517(vs).

\subsubsection{Synthesis of $\left\{\left[\mathrm{Cu}\left(\mathrm{C}_{5} \mathrm{H}_{4} \mathrm{O}_{6}\right)(\text { bipy) }] \cdot 5 \mathrm{H}_{2} \mathrm{O}\right\}_{n}\right.$ (2)}

A mixture of tartaric acid $(0.132 \mathrm{~g}, 0.89 \mathrm{mmol})$, bipy $(0.188 \mathrm{~g}, \quad 0.52 \mathrm{mmol}), \quad \mathrm{NaOH} \quad(0.080 \mathrm{~g}, \quad 2 \mathrm{mmol})$,
$\mathrm{CuCl}_{2} \cdot 2 \mathrm{H}_{2} \mathrm{O}(0.112 \mathrm{~g}, 0.065 \mathrm{mmol}), \mathrm{CH}_{3} \mathrm{OH}(6 \mathrm{~mL})$ and distilled water $(12 \mathrm{~mL})$ was stirred for $5 \mathrm{~min}$ in air, then transferred and sealed in a $25 \mathrm{~mL}$ Teflon-lined autoclave, which was heated at $140^{\circ} \mathrm{C}$ for $72 \mathrm{~h}$. The autoclave was cooled over a period of $10 \mathrm{~h}$ at a rate of $5{ }^{\circ} \mathrm{C} \mathrm{h}^{-1}$, to yield a very fine blue crystalline product $\mathbf{2}$ in $38 \%$ yield. Anal. Calc. for $\mathrm{C}_{14} \mathrm{H}_{10} \mathrm{CuN}_{2} \mathrm{O}_{11}$ (2): C, 38.58; $\mathrm{H}, 4.10 ; \mathrm{N}$, 6.00. Found: C, 38.88; H, 4.01; N, 5.86\%. IR $(\mathrm{KBr}$, $\mathrm{cm}^{-1}$ ) for 2: 3418(vs), 1616(vs), 1597(m), 1395(vs), 1297(m), 1222(m), 1078(vs), 1025(vs), 814(m), 611(m), $516(\mathrm{~m})$.

\subsubsection{Synthesis of $\left\{\left[\mathrm{Cu}\left(\mathrm{C}_{4} \mathrm{H}_{4} \mathrm{O}_{5}\right)(\mathrm{bpa})\right] \cdot 2.5 \mathrm{H}_{2} \mathrm{O}\right\}_{n}$ (3)}

A mixture of malic acid $(0.132 \mathrm{~g}, 0.99 \mathrm{mmol}), \mathrm{KOH}$ $(0.080 \mathrm{~g}, 2 \mathrm{mmol}), \mathrm{CuCl}_{2} \cdot 2 \mathrm{H}_{2} \mathrm{O}(0.112 \mathrm{~g}, 0.065 \mathrm{mmol})$, bpa $(0.032 \mathrm{~g}, 0.0172 \mathrm{mmol}), \mathrm{CH}_{3} \mathrm{OH}(4 \mathrm{~mL})$ and distilled water $(12 \mathrm{~mL})$ was stirred for $5 \mathrm{~min}$ in air, then transferred and sealed in a $25 \mathrm{~mL}$ Teflon-lined autoclave, which was heated at $140{ }^{\circ} \mathrm{C}$ for $72 \mathrm{~h}$. The autoclave was cooled over a period of $10 \mathrm{~h}$ at a rate of $5{ }^{\circ} \mathrm{C} \mathrm{h}^{-1}$, to yield a very fine blue crystalline product 3 in $38 \%$ yield. Anal. Calc. for $\mathrm{C}_{16} \mathrm{H}_{20} \mathrm{CuN}_{2} \mathrm{O}_{7.50}$ (3): $\mathrm{C}, 33.45 ; \mathrm{H}, 3.30 ; \mathrm{N}, 4.59$. Found: $\mathrm{C}, 33.60 ; \mathrm{H}, 3.26 ; \mathrm{N}, 4.56 \%$. IR $\left(\mathrm{KBr}, \mathrm{cm}^{-1}\right)$ for 3 : IR (KBr, $\mathrm{cm}^{-1}$ ) 3414(s), 2919(w), 1639(vs), 1503(vs), 1426(s), 1220(s), 1030(m), 843(m), 628(w), 519(m).

\section{X-ray crystallography}

Single crystal X-ray data of 1-3 were collected at $298 \mathrm{~K}$ on a Bruker SMART APEX CCD diffractometer using graphite-monochromatic Mo $\mathrm{K} \alpha$ radiation $(\lambda=$ $0.71073 \AA$ ). The crystal data and structure refinement of compounds 1-3 are summarized in Table 1. The linear absorption coefficients, scattering factors for the atoms, and the anomalous discussion corrections were taken from International Tables for X-ray Crystallography. The data integration and reduction were processed with SAINT software [24]. The structures were solved by the direct method using SHELXTL and were refined on $F^{2}$ with SHELXL-97 program package [25]. All non-hydrogen atoms present were anisotropically refined. All hydrogen atoms of water were located in successive different Fourier Maps and the other hydrogen atoms were treated as riding method.

\section{Results and discussion}

\subsection{Syntheses of the complexes}

All the complexes were obtained by solvothermal reactions of transition-metal salts with the hydroxyl polycarboxylates and assistant ligands in water at temperature of $140{ }^{\circ} \mathrm{C}$. Some variations of the starting materials that may have influenced on the assembly process including metal salts, assistant ligand and $\mathrm{pH}$. No other kinds of crystals were obtained, however, suggesting the stability of the final structures in the hydrothermal conditions. 
Table 1

Crystallographic data and structure refinement for 1-3

\begin{tabular}{llll}
\hline & $\mathbf{1}$ & $\mathbf{2}$ & $\mathbf{3}$ \\
\hline Formula & $\mathrm{C}_{22} \mathrm{H}_{24} \mathrm{CoN}_{3} \mathrm{O}_{8}$ & $\mathrm{C}_{14} \mathrm{H}_{10} \mathrm{CuN}_{2} \mathrm{O}_{11}$ & $\mathrm{C}_{16} \mathrm{H}_{20} \mathrm{CuN}_{2} \mathrm{O}_{7.5}$ \\
Molecular weight & 517.37 & 445.78 & 407.88 \\
Crystal system & triclinic & orthorhombic & orthorhombic \\
Space group & $P \overline{1}$ & $P 2_{1} 2_{1} 2_{1}$ & $F d d 2$ \\
$a(\AA)$ & $7.5814(8)$ & $6.6556(8)$ & $21.9944(13)$ \\
$b(\AA)$ & $12.6006(13)$ & $14.3048(16)$ & $33.3369(19)$ \\
$c(\AA)$ & $13.6456(14)$ & $19.047(2)$ & $10.3969(5)$ \\
$\alpha\left({ }^{\circ}\right)$ & $67.3630(10)$ & 90 & 90 \\
$\beta\left({ }^{\circ}\right)$ & $74.9070(10)$ & 90 & 90 \\
$\gamma\left({ }^{\circ}\right)$ & $76.6100(10)$ & 90 & 90 \\
$V\left(\AA^{3}\right)$ & $1148.9(2)$ & $1813.4(4)$ & $7623.3(7)$ \\
$Z$ & 2 & 4 & 16 \\
$D_{\text {calc. }}\left(\mathrm{g} / \mathrm{cm}^{3}\right)$ & 1.495 & 1.633 & 1.477 \\
$\left.\theta \mathrm{Range}^{\circ}\right)$ & $1.65-26.00$ & $1.78-24.50$ & $2.22-27.50$ \\
$\mu\left(\mathrm{mm}{ }^{-1}\right)$ & 0.800 & 1.267 & 1.188 \\
$F(000)$ & 536 & 900 & 3504 \\
Parameters & 335 & 223 & 260 \\
Goodness-of-fit & 1.016 & 1.093 & 1.030 \\
$R_{1}[I>2 \sigma(I)]^{\mathrm{a}}$ & 0.0528 & 0.0851 & 0.0546 \\
$w R_{2}(\text { all data })^{\mathrm{b}}$ & 0.1308 & 0.2469 & 0.1730 \\
\hline${ }^{\mathrm{a}} R^{1}=\sum\left\|F_{\mathrm{o}}|-| F_{\mathrm{c}}\right\| / \sum\left|\mathrm{F}_{\mathrm{o}}\right|$. & \\
${ }_{\mathrm{b}}{ }_{w R_{2}}=\left\{\sum\left[w\left(F_{\mathrm{o}}^{2}-F_{\mathrm{c}}^{2}\right)^{2}\right] / \sum\left(F_{\mathrm{o}}^{2}\right)^{2}\right\}^{1 / 2}$. & \\
& & &
\end{tabular}

\section{2. $\left\{\left[\mathrm{Co}\left(\mathrm{C}_{4} \mathrm{H}_{4} \mathrm{O}_{5}\right)(\text { bpe })\left(\mathrm{H}_{2} \mathrm{O}\right)_{2}\right] \cdot(0.5 b p e)\left(\mathrm{H}_{2} \mathrm{O}\right)\right\}_{n}(\mathbf{1})$}

The asymmetric unit contains one $\mathrm{Co}^{2+}$ cation, one $\mathrm{Hmal}^{2-}$ anion $\left(\mathrm{Hmal}^{2-}=\right.$ malate dianion), two coordination water molecules and one lattice water molecule, and half exoteric bpe molecule and one bridging bpe ligand. As depicted in Fig. 1. The bpe ligand serves as a bridge to connect two Co atoms, leading to a 1D chain running along the $a$ direction. Each $\mathrm{Co}^{2+}$ ion is located on a symmetry center and octahedral coordination formed by two oxygen atoms of one malate and two aqua ligands and two $\mathrm{N}$ atoms of two separated bpe ligands in trans-position. The $\mathrm{Co}-\mathrm{O}$ bond distances fall in the region 2.053(3)-2.119(2) $\AA$, and $\mathrm{Co}-\mathrm{N}$ bond distance averaging $2.15 \AA$ are practically identical with the experimental limitation (Table 2). Thus, a zigzag Co-bpe-Co chain with Co $\cdots$ Co separation $13.646 \AA$ is formed. The neighboring inter-chain Co...Co distance is 7.581(5) $\AA$. The dihedral angle between the two pyridyl rings of the bpe is $9.2(2)^{\circ}$, dissimilar to those observed in other polymers [26-28].

It is interesting that the neighboring $\mathrm{Co}(\mathrm{II})$ atoms in $\mathbf{1}$ are bridged by bpe ligands rather than multifunctional malate dianion which coordinates to the cobalt center through

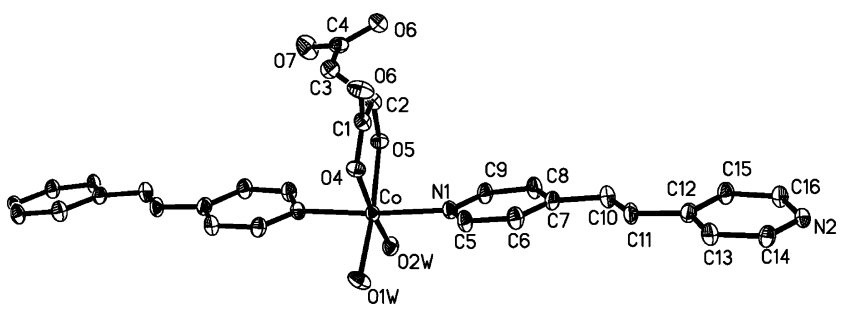

Fig. 1. Octahedral coordination spheres of Co ion in compound 1 with atom labeling schemes; hydrogen atoms are omitted for clarity.
Table 2

Selected bond distances $(\AA)$ and angles $\left({ }^{\circ}\right)$

\begin{tabular}{ll}
\hline 1 & \\
$\mathrm{Co}(1)-\mathrm{O}(2 \mathrm{~W})$ & $2.052(4)$ \\
$\mathrm{Co}(1)-\mathrm{O}(4)$ & $2.062(3)$ \\
$\mathrm{Co}(1)-\mathrm{O}(1 \mathrm{~W})$ & $2.082(4)$ \\
$\mathrm{Co}(1)-\mathrm{O}(5)$ & $2.119(2)$ \\
$\mathrm{Co}(1)-\mathrm{N}(1)$ & $2.148(3)$ \\
$\mathrm{O}(2 \mathrm{~W})-\mathrm{Co}(1)-\mathrm{O}(4)$ & $172.14(12)$ \\
$\mathrm{O}(1 \mathrm{~W})-\mathrm{Co}(1)-\mathrm{O}(5)$ & $168.98(12)$ \\
$\mathrm{N}(1)-\mathrm{Co}(1)-\mathrm{N}(2)$ & $175.10(10)$ \\
& \\
2 & \\
$\mathrm{Cu}(1)-\mathrm{O}(2)$ & $1.978(10)$ \\
$\mathrm{Cu}(1)-\mathrm{O}(6) \# 1$ & $1.995(10)$ \\
$\mathrm{Cu}(1)-\mathrm{O}(5) \# 1$ & $2.277(11)$ \\
$\mathrm{Cu}(1)-\mathrm{O}(1)$ & $2.295(10)$ \\
$\mathrm{Cu}(1)-\mathrm{N}(1)$ & $1.977(6)$ \\
$\mathrm{Cu}(1)-\mathrm{N}(1)$ & $1.968(5)$ \\
$\mathrm{N}(1)-\mathrm{Cu}(1)-\mathrm{O}(6) \# 1$ & $159.2(4)$ \\
$\mathrm{N}(2)-\mathrm{Cu}(1)-\mathrm{O}(5) \# 1$ & $111.0(4)$ \\
$\mathrm{N}(2)-\mathrm{Cu}(1)-\mathrm{O}(2)$ & $159.1(4)$ \\
$\mathrm{O}(1)-\mathrm{Cu}(1)-\mathrm{O}(5) \# 1$ & $154.5(3)$ \\
3 & \\
$\mathrm{Cu}(1)-\mathrm{O}(4)$ & \\
$\mathrm{Cu}(1)-\mathrm{O}(5)$ & $1.941(3)$ \\
$\mathrm{Cu}(1)-\mathrm{N}(2)$ & $1.987(4)$ \\
$\mathrm{Cu}(1)-\mathrm{N}(1)$ & $1.995(5)$ \\
$\mathrm{Cu}(1)-\mathrm{O}(2)$ & $2.011(4)$ \\
$\mathrm{O}(5)-\mathrm{Cu}(1)-\mathrm{N}(2)$ & $2.335(4)$ \\
$\mathrm{O}(4)-\mathrm{Cu}(1)-\mathrm{N}(1)$ & $175.37(18)$ \\
\hline$\# 1+11, z .99(19)$ \\
\end{tabular}

$\# 1 x+1, y, z$.

two oxygen atoms of alkoxy and $\alpha$-carboxylate groups. The malate adopts the mode I fashion [20], while the $\beta$-carboxyl group is not deprotonated and remains freedom, as confirmed by the strong absorption band at $1692 \mathrm{~cm}^{-1}$ in the IR spectrum. This phenomenon has been found in three mononuclear structures [29-31]. These adjacent zigzag chains are further connected through hydrogen-bonding interactions $\quad[\mathrm{O} 1 \mathrm{w} \cdots \mathrm{O} 6=2.789(5) \AA \quad \mathrm{O} 1 \mathrm{w}-\mathrm{H} 1 \mathrm{w} \cdots \mathrm{O} 6=$ $165(5)^{\circ}$; symmetry code: $-x+1,-y+1, z ; \mathrm{O} 2 \mathrm{w} \cdots \mathrm{O} 8=$ $2.712(4) \AA \mathrm{O} 2 \mathrm{w}-\mathrm{H} 3 \mathrm{w} \cdots \mathrm{O} 8=173(5)^{\circ}$; symmetry code: $x-1, y, z]$ between the coordinated water molecules and uncoordinated oxygen atoms of carboxylate groups, leading to a $2 \mathrm{D}$ structural motif in the $a c$ plane as illustrated in Fig. 2. The free bpe molecules reside at the crossing positions of the square grid sheets. These $2 \mathrm{D}$ sheets are linked into a $3 \mathrm{D}$ network through another hydrogen bondings produced by lattice water with one non-coordinated bpe molecule, forming a large channel, as shown in Fig. S1.

\section{3. $\left\{\left[\mathrm{Cu}\left(\mathrm{C}_{4} \mathrm{H}_{4} \mathrm{O}_{6}\right)(\text { bipy })\right] \cdot 5 \mathrm{H}_{2} \mathrm{O}\right\}_{n}($ 2)}

A single-crystal X-ray structural analysis shows that $\mathbf{2}$ crystallizes in orthorhombic chiral space group $P 2{ }_{1} 2_{1} 2_{1}$, with one copper(II) atom, one quadridentate tartrate ligand, one bipy ligand, and five lattice water molecules 


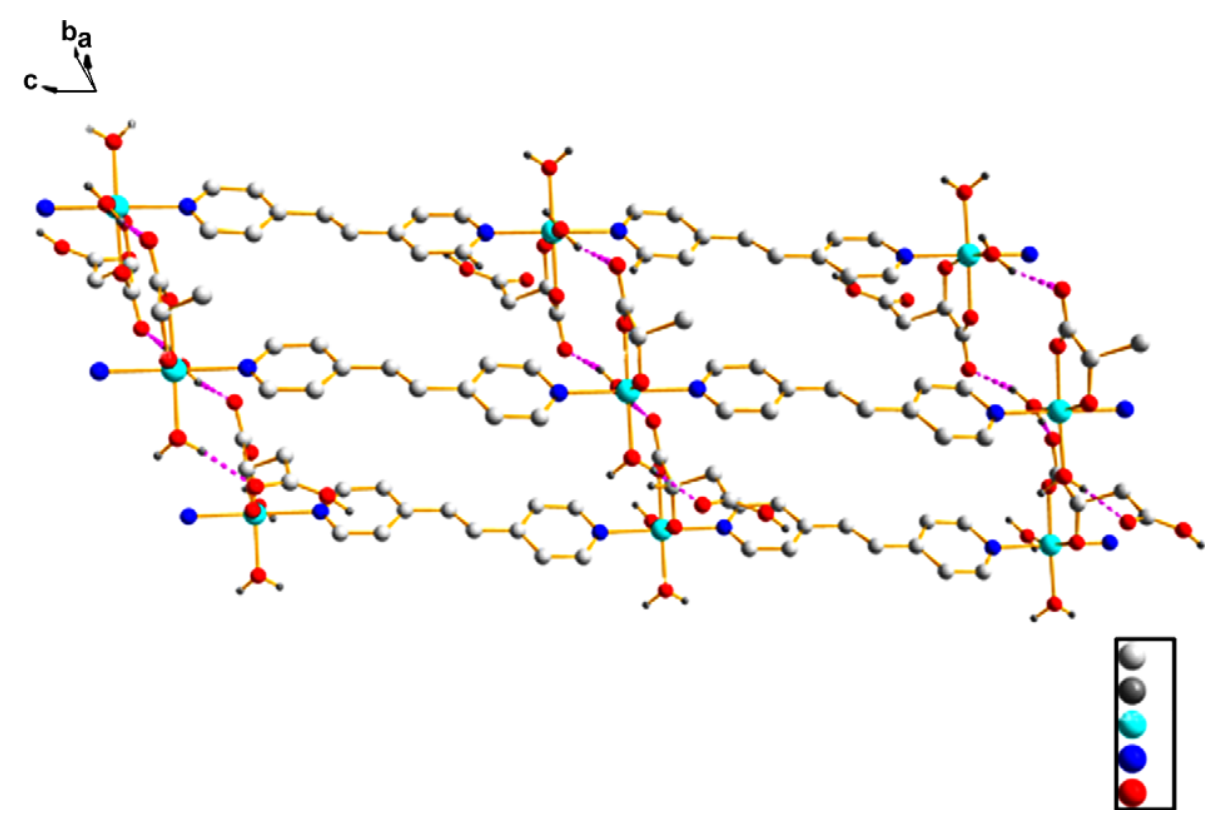

Fig. 2. Two-dimensional sheet in compound $\mathbf{1}$ formed through hydrogen bonding between uncoordinated carboxylate group of malic acid and coordinated water molecules in the $b$ axis. Symmetry codes: (1) $\mathrm{Cu}-\mathrm{O}_{2}: x, y, z$; (2) $\mathrm{Cu}-\mathrm{O}_{5}: 1+x, y, z$.

in each crystallographic unit, as shown in Fig. 3. Each copper(II) ion is coordinated by four oxygen atoms from two different tartrate ligands, and two nitrogen atoms from a chelating bipy ligand to give $[2+2+2]$ distorted octahedral geometry. The corresponding bond parameters in $\mathbf{2}$ are in close agreement with previous copper(II) complexes containing carboxylate ligands. In addition, the fact that the $\mathrm{Cu}-\mathrm{O}_{\text {(carboxyl) }}$ bonds [av. 1.987(10)] are significantly shorter than the $\mathrm{Cu}-\mathrm{O}_{\text {(hydroxyl) }}$ bond [av. 2.86(10)], in which is also found in other complexes [19,32-35].

It is worthwhile to note that the tartrate ligand bridges to the copper center to form a $1 \mathrm{D}$ polymeric chain running along the crystallographic $a$ axis with adjacent $\mathrm{Cu} \cdots \mathrm{Cu}$ distance of $6.656 \AA$. The bipy ligands lie on one side of this chain in parallel fashion. Interestingly, a pair of 1D chains self-assembles to generate a molecular zipper-like double chain under the direction of strong aromatic $\pi-\pi$ interactions between the bipy units with a face-to-face distance of ca. 3.122-3.356 $\AA$ (Fig. 4). Such zipper-like chain structures are notable common, but so far, few examples of zipper-like coordination polymers have been reported. To the

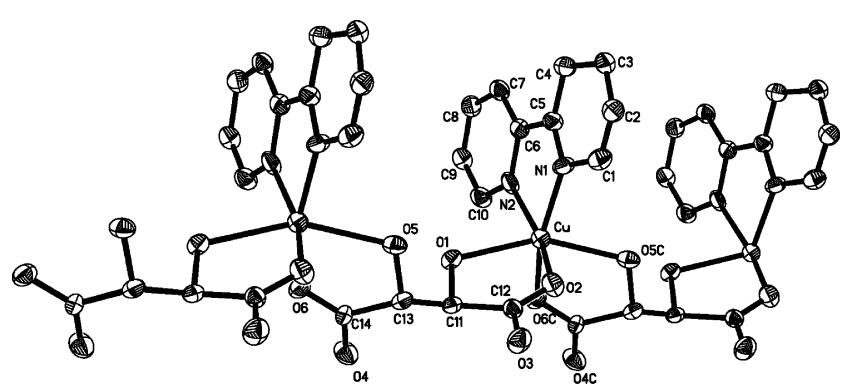

Fig. 3. ORTEP diagram showing the coordination environments for metal atoms in $\mathbf{2}$ (the lattice water molecules are omitted for clarity).

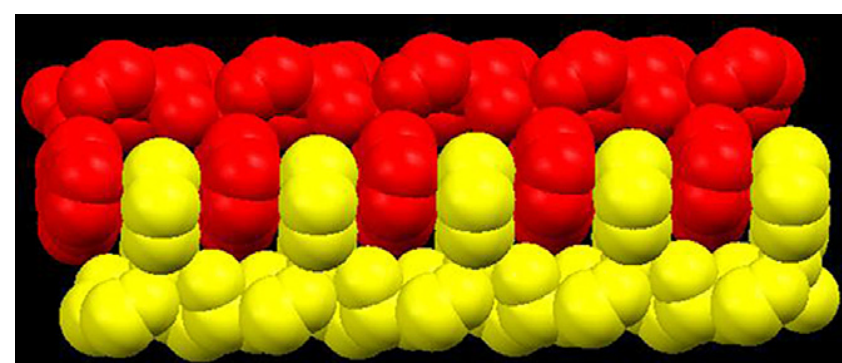

Fig. 4. View of the double-stranded polymeric chain in $\mathbf{2}$.

best of our knowledge, the zipper-like double chains represent an example of perfect molecular double chains using tartrate ligand. The unique feature of compound $\mathbf{2}$ is the interesting arrangement of tartrate molecule and coordination of copper atom forming helical structure, which is constructed by flexible $\mathrm{O}_{2} \mathrm{C}-\mathrm{C}-\mathrm{C}-\mathrm{CO}_{2}$ groups bridging between the $\mathrm{Cu}$ centers along $a$ direction with a pitch of $6.8 \AA$. The formation of the helix in the structure may be attributed to the fact that the steric orientation of the carboxyl groups is expected.

The most remarkable feature of $\mathbf{2}$ is that, the hydrogen bonding association of water molecules leading to the formation of a cyclic water pentamer consisting of one $\mathrm{O} 11 \mathrm{~W}$, two symmetry-related $\mathrm{O} 7 \mathrm{~W}$ and $\mathrm{O} 9 \mathrm{~W}$, whose conformation is similar to another water cluster reported by Gao and his co-workers [36]. In addition, $\mathrm{O} 8 \mathrm{~W}$ and $\mathrm{O} 10 \mathrm{~W}$, bond jointly to the water molecule $(\mathrm{O} 7 \mathrm{~W})$ and form a dimer. The water molecules of the dimeric and pentameric water cluster are hydrogen bonded to carboxylate oxygen atoms (O3 and $\mathrm{O} 5)$ and unprotonated hydroxyl groups (O1), resulting in an overall 3D framework that features 1D open channels viewed along the crystallographic $a$ axis. 
The approximate dimensions of these channels are $10.51 \times 5.82 \AA^{2}$, which are large enough to encapsulate guest solvent molecules.

The water pentamer topology described here is in agreement with the puckered ring achieved from both experimental and theoretical studies by Liu, Saykally and their coworkers [37]. The bent angle of water pentamer in $\mathbf{2}$ is $45.8^{\circ}$, which is considerably larger than that of the discrete pentamer (ca. $20^{\circ}$ ), but is shorter than the water tape $\left(52.2^{\circ}\right)[36]$. The differences may be attributed to the influence of surrounding environments. The $\mathrm{O} \cdots \mathrm{O}$ distances within the pentamer range from 2.681(5) to 2.925(3) $\AA$ (Table S3). Adjacent pentamers are fused together by sharing one edge, forming a one-dimensional water tape along [0 10$]$ direction (Fig. 5). According to Infantes' classification [38], those water tapes in $\mathbf{2}$ have the symbol T5(2). The average $\mathrm{O} \cdots \mathrm{O}$ distance within the tape is $2.805 \AA$ ( $298 \mathrm{~K})$, which is closed to the corresponding value of $2.85 \AA$ found in liquid water, indicating a great structural resemblance to liquid water and comparable to those in the ice(II) phase (2.77-2.84 ̊) [39].

\section{4. $\left\{\left[\mathrm{Cu}\left(\mathrm{C}_{4} \mathrm{H}_{4} \mathrm{O}_{5}\right)(\mathrm{bpa})\right] \cdot 2.5 \mathrm{H}_{2} \mathrm{O}\right\}_{n}(3)$}

Single crystal diffraction analysis reveals that $\mathbf{3}$ contains one bpa molecule, one $\mathrm{Hmal}^{2-}$ anion $\left(\mathrm{Hmal}^{2-}=\right.$ malate dianion), and two half water molecules in the asymmetric unit, as shown in Fig. 6. Each $\mathrm{Cu}$ (II) ion is six-coordinated by two nitrogen atoms from two bpa molecules, four oxygen atoms from two $\mathrm{Hmal}^{2-}$ anions, forming an axially elongated $[4+1+1]$ octahedral geometry. The adjacent $\mathrm{Cu}^{2+}$ ions are linked by two bpa ligands with gauchegauche conformation, which result a square grid with a window of about $8.7 \times 9.6 \AA$. Guest water molecules are found in this grid. These square grids are transversally joined by $\mathrm{Hmal}^{2-}$ anions and show $\mathrm{Cu} \cdot \mathrm{Cu}$ separation of 5.97(5) А. The $\beta$-caboxylate group bridges neighboring metal centers, in which is similar to that found in $[\mathrm{Cu}(\mathrm{H}-$ $\left.\mathrm{mal})(4 \mathrm{pds}) \cdot 6 \mathrm{H}_{2} \mathrm{O}\right] \quad$ and $\quad\left\{\left[\mathrm{Cu}(\mathrm{Hmal})(\mathrm{bpp}) \cdot 6 \mathrm{H}_{2} \mathrm{O}\right]\right\}_{n}$

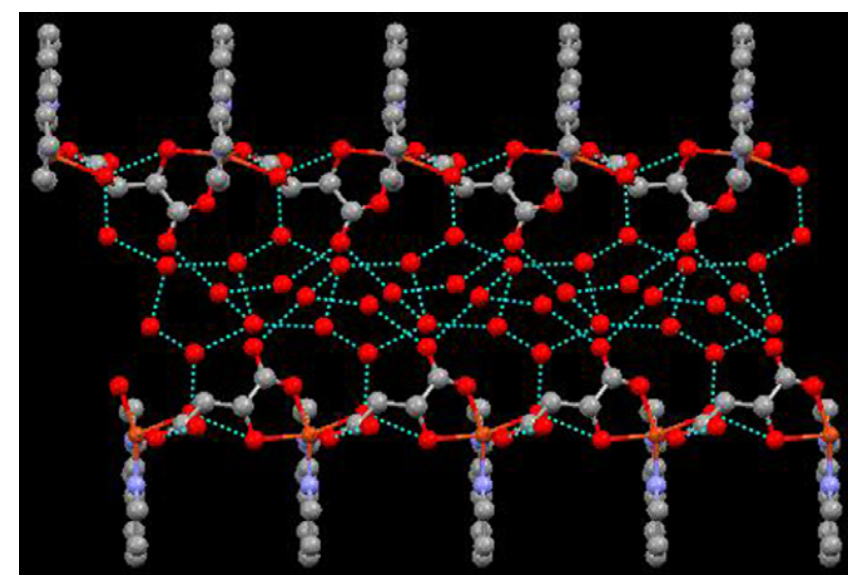

Fig. 5. A view showing how the self-assembled chain of water molecules are bound to the MOF in 2.

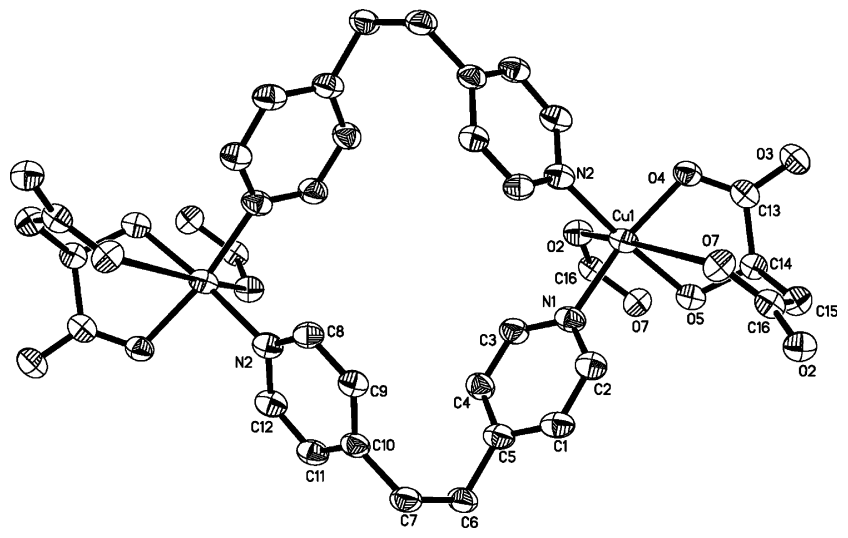

Fig. 6. ORTEP diagram showing the coordination environments for metal atoms in 3. Hydrogen atoms are omitted for clarity.

$[23,40]$. Therefore, the global structure should be described as $2 \mathrm{D}$ coordination polymer along the $a c$-plane, as shown in Fig. 7. There has a 36-membered $\left[\mathrm{Cu}_{6}(\mathrm{bppHmal})_{4}\right]$ ring as its basic motif, each ring with $13.7 \times 13.7 \AA$ encloses water pentamer, as shown in Fig. S2. Due to the $\mathrm{N}-\mathrm{Cu}-$ $\mathrm{N}$ bond angle of 93.4(8) $\AA$ and the flexibility of the bpa ligands, an interesting pipe-comb-like 2D layered structure with a channel of about $8.7 \times 9.6 \AA$ occurs in this net along the $a b$-plane (Fig. 8).

If, for reasons of classifying the net, we define chelated ring as a single point of connection to $\mathrm{Cu}$ (making each Hmal as effectively single linker), then $\mathrm{Cu}$ atoms are depicted as three-connected nodes, the framework can be represented simply by connecting the $\mathrm{Cu}$ nodes according to the connectivity defined by the bridging Hmal and bpa ligands (Scheme S1). This type of network is referred to a common example of $6^{3}$ topology [41], as shown in Fig. 9a. Each $\mathrm{Cu}(\mathrm{II})$ is linked to six other radiative $\mathrm{Cu}(\mathrm{II})$

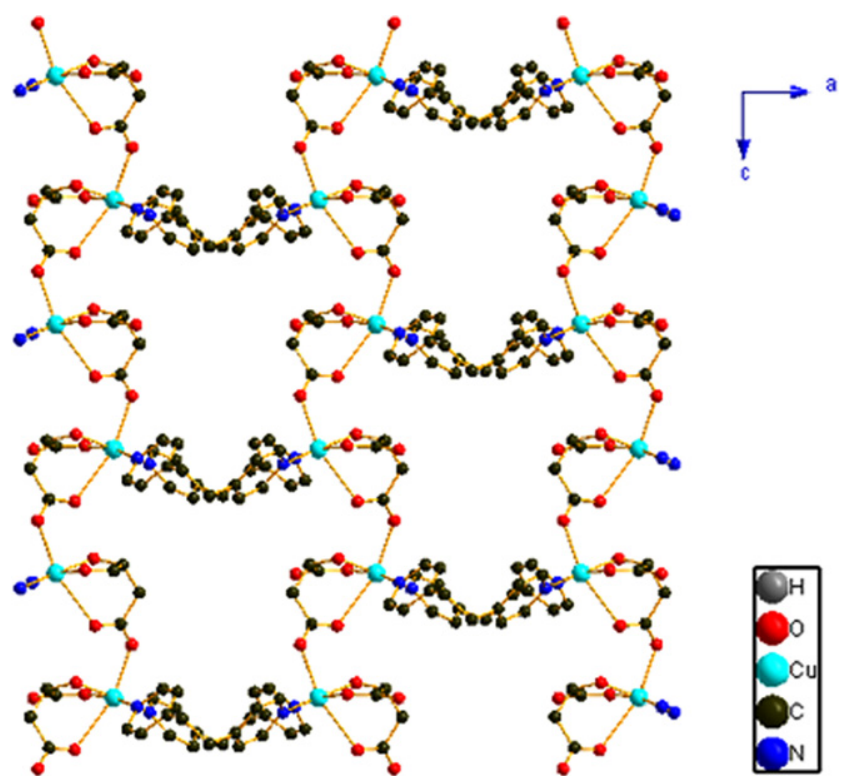

Fig. 7. View of the "MD" sheet in $\mathbf{3}$ along $a c$-plane. 


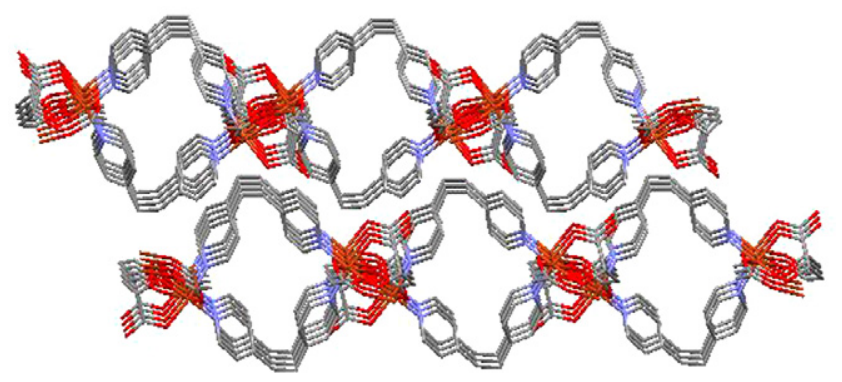

Fig. 8. A view of net along the ab plane in $\mathbf{3}$ showing an interesting a pipecomb-like 2D layer structure: the hydrogen atoms are omitted for clarity.
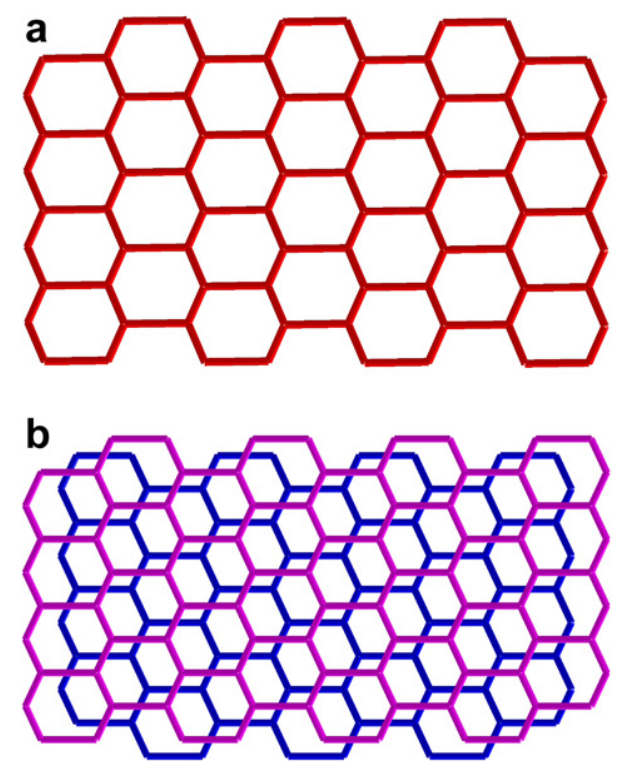

Fig. 9. (a) Schematic illustration the $(6,3)$ topology of $2 \mathrm{D}$ network of $\mathbf{3}$; (b) two parallel off-set double-layer in $\mathbf{3}$.

ions, and every three neighboring $\mathrm{Cu}(\mathrm{II})$ ions encircle a triangular hole. It should be noted that these hydrogen bonds and molecular forces result in adjacent $2 \mathrm{D}$ layer in $\mathbf{3}$ stacked in a slightly offset parallel fashion with $\mathrm{ABAB}$ sequence forming non-interpenetrating 3D array (Fig. 9b).

\subsection{Thermogravimetric analysis and X-ray powder diffraction}

To investigate the thermal stability of polymers $\mathbf{2}$ and $\mathbf{3}$, the samples were analyzed by TGA under nitrogen. The TGA data of $\mathbf{2}$ and $\mathbf{3}$ suggest that there are three stages of weight loss in the temperature range (Fig. S3). The major weight losses occur above ca. $175^{\circ} \mathrm{C}$ in 2 , corresponding to the lattice water molecules and the tartrate and bipy ligands, respectively. As expected from its structure, compound 3 loses lattice water molecules in 43$140{ }^{\circ} \mathrm{C}(10.4 \%$ observed, $11.3 \%$ calcd $)$. The next weigh loss occurs below $300{ }^{\circ} \mathrm{C}$ to give a total weigh loss of ca. $74.4 \%$, corresponding to the malate and bpa ligands. To confirm the TGA, the original sample of $\mathbf{3}$ was characterized by
X-ray Powder diffraction (XRPD) at a wide temperature range $\left(25-450{ }^{\circ} \mathrm{C}\right)\left(\mathrm{Fig}\right.$. S4). At $300^{\circ} \mathrm{C}$, the XRD pattern changes completely, revealing the collapse of the framework, which is in accordance with the result of the thermogravimetric analysis.

\subsection{Magnetic study}

The temperature dependence of the magnetic susceptibilities for complex 1 in the range $2-300 \mathrm{~K}$, and shown as $\chi_{\mathrm{M}} T$ and $\chi_{\mathrm{M}}$ versus $T$ plots in Fig. S5. The experimental $\chi_{\mathrm{M}} T$ curve exhibits a continuous decrease from $300 \mathrm{~K}$ to $2 \mathrm{~K}$ as the temperature is lowered for the compound. Such behavior is characteristic for $\mathrm{Co}$ (II) complex, essentially due to the single ion anisotropy, and may combine some contribution of anti-ferromagnetic exchange between the $\mathrm{Co}(\mathrm{II})$ centers.

Based on the structural information, the magnetic coupling mediated by Van der Waals interactions between the chains could be negligibly small. We have attempted to fit the experimental susceptibility using the classical spin Heisenberg model for a one-dimensional chain [42].

$\chi_{\mathrm{M}}=\frac{N g^{2} \beta^{2} S(S+1)}{3 K T} \frac{1+u}{1-u}$,

where $u(K)=\operatorname{coth}(K)-1 / K$.

$K=2 J S(S+1) / K T S=3 / 2$.

An additional coupling parameter, $z J^{\prime}$, was added in Eq. (2) to take into account the magnetic behavior through hydrogen bonding interaction between 1D chains [43].

The total magnetic susceptibility is

$\chi_{\mathrm{T}}=\frac{\chi_{\mathrm{M}}}{1-\frac{2 z J^{\prime}}{N \beta^{2} g^{2}} \chi_{\mathrm{M}}}$.

The least-squares analysis of magnetic susceptibilities data led to $J=-0.27 \mathrm{~cm}^{-1}, g=2.05, z J^{\prime}=-0.031 \mathrm{~cm}^{-1}$ and $R=4.02 \times 10^{-3}$ for 1 . The agreement factor defined as $R=\sum\left[\left(\chi_{\mathrm{M}} T\right)_{\mathrm{obs}}-\left(\chi_{\mathrm{M}} T\right)_{\text {calc }}\right]^{2} / \sum\left[\left(\chi_{\mathrm{M}} T\right)_{\mathrm{obs}}\right]^{2}$. The $J$ value indicates a weak anti-ferromagnetic between the nearest $\mathrm{Co}$ (II) ions bridged by bpe. The smaller negative $z J^{\prime}$ value can be assigned to a very weak anti-ferromagnetic interaction through hydrogen-bonding interactions. Obviously, the result is not very satisfactory, especially in low temperature region. The inclusion of an interaction based on the molecular field approximation does not improve the theoretical fitting distinctly. This may original from the fact that Fisher's equation does not take into account the effects of the zero-field splitting and/or spin-orbit coupling which are significant for $\mathrm{Co}(\mathrm{II})[44,45]$.

\subsection{Photoluminescence}

The emissions spectra of complexes $\mathbf{1}-\mathbf{3}$ in the solid state at room temperature are shown in Fig. S6. While the 1-3 of analogous pyridine, it can be observed that the emission occurring in the same range for the two different metals 


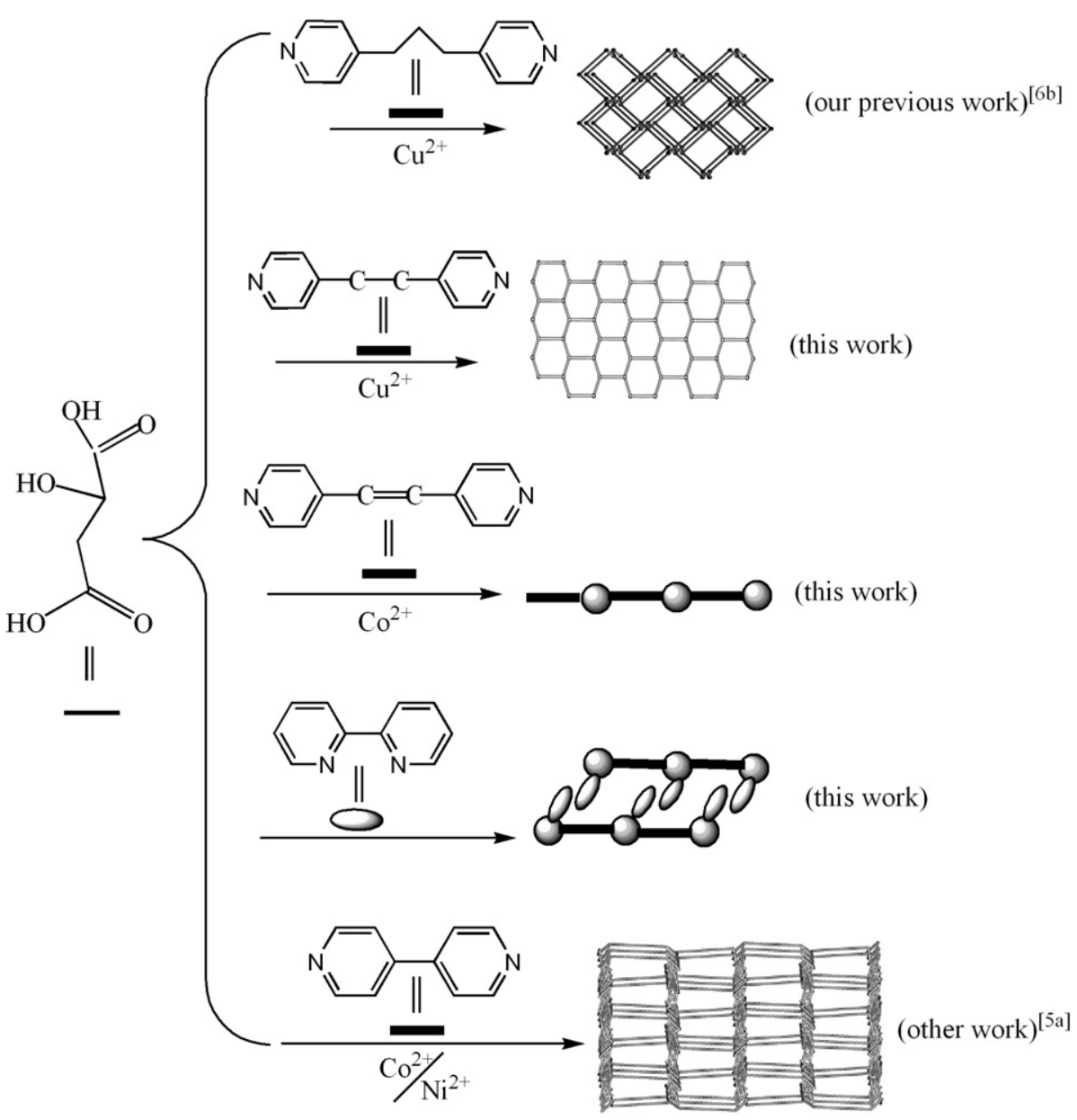

Scheme 1.

can be assigned to ligand-to-metal charge transfer (LMCT) bands. Similar to those observed for dipyridine other ligands $[46,47]$ (Fig. S6 $a$ : $\lambda_{\mathrm{ex}}=300 \mathrm{~nm}, \lambda_{\mathrm{em}}=391 \mathrm{~nm}$ for 1; $b: \lambda_{\mathrm{ex}}=335 \mathrm{~nm}, \lambda_{\mathrm{em}}=365 \mathrm{~nm}$ for $2 ; c: \lambda_{\mathrm{ex}}=330 \mathrm{~nm}$, $\lambda_{\mathrm{em}}=383 \mathrm{~nm}$ for $\mathbf{3}$ ).

The UV-Vis spectra of complexes 1-3 are recorded in methanol and characterized by several spectral regions (Fig. S7). The absorption bands in the range of 260 $285 \mathrm{~nm}$ for the bpe and $228-285 \mathrm{~nm}$ for the bipy ligand are ligand-centered (LC) due to $\pi-\pi^{*}$ transitions. The peaks at $254 \mathrm{~nm}$ for complexes $\mathbf{1}$ and $\mathbf{2}$ are assigned to metal-toligand charge transfer transitions (MLCT) [48]. This great shift of absorption bands of the complexes relative to that of the bpe and bipy ligands are caused by the effects of metal-to-ligand charge transfer transitions. The absorption bands of the complex $\mathbf{3}$ and the bpa occur at the same region $(256 \mathrm{~nm})$ due to absence of conjugated system for bpa ligand.

\section{Conclusion}

In conclusion, the self-assembly of three polymeric complexes with chains or layer were constructed from two types of hydroxycarboxylic acids in the presence of multi-dentate
$\mathrm{N}$-donor auxiliary ligands under solvothermal conditions. The auxiliary ligands play an important role in the synthesis of the complexes. In $\mathbf{1}$ and $\mathbf{2}$, the tartrate and malate in combination with terminated and rigid ligands, respectively, only exhibit 1D chain systems, while in $\mathbf{3}$, the single-connecting malate cooperates with the flexible bpa, forming a $6^{3}$ topological architecture.

We have concluded our investigations in this report and previous reports, which were coordination polymers of transition metal containing malic acid in combination with multi-dentate $\mathrm{N}$-donor ligands (Scheme 1). The work shows that the conformations and the functions of ligands play an important role in affecting the final structural motifs. Further studies involving other hydroxycarboxylic acid in combination with multi-dentate $\mathrm{N}$-donor ligands are in progress. Investigation of the different coordination modes of the ligands may also help in design of new structural framework and fabrication of new functional material.

\section{Acknowledgements}

This work was supported by the National Natural Science Foundation of China (Nos. 20471048 and 20771090) 
and TRAPOYT, and Specialized Research Found for the Doctoral Program of Higher Education (No. 20050697005).

\section{Appendix A. Supplementary material}

CCDC 631996, 631997 and 631998 contains the supplementary crystallographic data for $\mathbf{1}, \mathbf{2}$ and $\mathbf{3}$. These data can be obtained free of charge from The Cambridge Crystallographic Data Centre via www.ccdc.cam.ac.uk/data_request/cif. Supplementary data associated with this article can be found, in the online version, at doi:10.1016/ j.ica.2007.11.036.

\section{References}

[1] S. Leininger, B. Olenyuk, J.P. Stang, Chem. Rev. 100 (2000) 853.

[2] G.F. Swiegers, T.J. Malefetse, Chem. Rev. 100 (2000) 3483.

[3] P.J. Hagrman, D. Hagrman, J. Zubieta, Angew. Chem., Int. Ed. 38 (1999) 2638.

[4] Q.-D. Liu, J.-R. Li, S. Gao, B.-Q. Ma, H.-Z. Kou, L. Ouyang, R.-L. Huang, X.-X. Zhang, K.-B. Yu, Eur. J. Inorg. Chem. (2003) 731.

[5] B.-Q. Ma, S. Gao, G. Su, G. Xu, Angew. Chem., Int. Ed. 40 (2001) 434.

[6] W.-F. Yeung, W.-L. Man, W.-Y. Wong, T.-C. Lau, S. Gao, Angew. Chem., Int. Ed. 41 (2001) 3031.

[7] J.-S. Seo, D. Wang, H. Lee, J. Oh, Y.J. Jeon, K. Kim, Nature (London) 404 (2000) 982.

[8] W. Lin, O.-R. Evans, R.-G. Xiong, Z.-J. Wang, J. Am. Chem. Soc. 120 (1998) 13272.

[9] D. Cave, J.M. Gascon, A.D. Bond, S.J. Teat, P.T. Wood, Chem. Commun. (2002) 1050.

[10] W.H. Jones, Catalysis in Organic Synthesis, nineth ed., Academic Press, New York, 1980.

[11] G. Rousselet, C. Chassagnard, P. Capdevielle, M. Maumy, Tetrahedron Lett. 37 (1996) 8497.

[12] G. Blay, I. Fernandez, T. Gimenez, J.R. Pedro, R. Ruiz, E. Prdo, F. Lloret, M.C. Munoz, Chem. Commun. (2001) 2102.

[13] B. Zhao, L. Yi, Y. Dai, X.-Y. Chen, P. Cheng, D.-Z. Liao, S.-P. Yan, Z.-H. Jiang, Inorg. Chem. 44 (2005) 911.

[14] P. Lightfoot, A. Sueddden, J. Chem. Soc., Dalton Trans. (1999) 3549.

[15] C. Qin, X.-L. Wang, E.-B. Wang, L. Xu, J. Mol. Struct. 738 (2005) 91.

[16] X.-M. Zhang, M.-L. Tong, M.-L. Gong, X.-M. Chen, Eur. J. Inorg. Chem. (2003) 138.

[17] S.K. Ghosh, P.K. Bharadwaj, Eur. J. Inorg. Chem. (2005) 4880.

[18] L.-M. Duan, F.-T. Xie, X.-Y. Chen, Y. Chen, Y.-K. Lu, P. Cheng, J.Q. Xu, Cryst. Growth Des. 6 (2006) 1101.

[19] A. Beghidja, P. Rabu, G. Rogez, R. Welter, Chem. Eur. J. 12 (2006) 7627.
[20] F.-T. Xie, L.-M. Duan, J.-Q. Xu, L. Ye, Y.-B. Liu, X.-X. Hu, J.-F. Song, Eur. J. Inorg. Chem. (2004) 4375.

[21] F.-T. Xie, L.-M. Duan, X.-Y. Chen, P. Cheng, J.-Q. Xu, H. Ding, T.G. Wang, Inorg. Chem. Commun. 8 (2005) 274.

[22] D.-S. Li, Y.-Y. Wang, X.-J. Luan, P. Liu, C.-H. Zhou, Q.-Z. Shi, Eur. J. Inorg. Chem. (2005) 2678.

[23] J.-Q. Liu, Y.-Y. Wang, P. Liu, W.-P. Wu, Y.-P. Wu, X.-R. Zeng, Q.Z. Shi, Inorg. Chem. Commun. 10 (2007) 343.

[24] SAINT Software for CCD Detector System, Siemens Analytical Instruments Division, Madison, WI, 1997.

[25] ShelXTL, Program Library for Structure Solution and Molecular Graphics, Siemens Analytical Instruments Division, Madison, WI, 1997.

[26] J.-H. Liao, S.-H. Cheng, H.-L. Tsai, C.I. Yang, Inorg. Chim. Acta 338 (2002) 1.

[27] D. Hagman, R.P. Hannond, R. Haushalter, J. Zubieta, Chem. Mater. 10 (1998) 2091.

[28] R. Wang, M.-C. Hong, D.-Q. Yuan, Y.-Q. Sun, L.-J. Xu, J.-H. Luo, R. Cao, A.S.C. Chan, Eur. J. Inorg. Chem. (2004) 37.

[29] R.D. Tatlor, P.G. Todd, N.D. Chasteen, J.T. Spence, Inorg. Chem. 18 (1979) 44.

[30] Z.-H. Zhou, W.-B. Yan, H.-L. Wan, K.-R. Tsai, J. Inorg. Biochem. 90 (2002) 137.

[31] Z.-H. Zhou, G.-F. Wang, S.-Y. Hou, H.-L. Wan, K.-R. Tsai, Inorg. Chim. Acta 314 (2001) 184.

[32] R.C. Bott, D.S. Sagatys, D.E. Lynch, G. Smith, C.H.L. Kennard, T.C.W. Mak, Aust. J. Chem. 44 (1991) 1495.

[33] X.-D. Chen, J.-H. Guo, M. Du, T.C.W. Mak, Inorg. Chem. Commun. 8 (2005) 766.

[34] B.-H. Ye, L.N. Ji, T.C.W. Mak, Polyhedron 17 (1998) 2687.

[35] M.-L. Tong, H.-K. Lee, Y.-X. Tong, X.-M. Chen, T.C.W. Mak, Inorg. Chem. 39 (2000) 4666

[36] B.-Q. Ma, H.-L. Sun, S. Gao, Chem. Commun. (2004) 2220.

[37] K. Liu, M.G. Brown, J.D. Cruzan, R.J. Saykally, Science 271 (1996) 62.

[38] L. Infantes, S. Motherwell, CrystEngComm (2002) 454.

[39] H. Narten, W.E. Thiessen, L. Blum, Science 217 (1982) 1033.

[40] R. Carballo, B. Covelo, E. García-Mrtínez, A.B. Lago, M. Vázquez, Growth Des. 6 (2006) 629.

[41] S.R. Batten, R. Robson, Angew. Chem., Int. Ed. 37 (1998) 1460.

[42] M.E. Fisher, Am. J. Phys. 32 (1964) 343.

[43] C.J. O'. Connor, Prog. Inorg. Chem. 29 (1982) 203.

[44] B.-Q. Ma, S. Gao, T. Yi, G.-X. Xu, Polyhedron 20 (2001) 1255.

[45] S. Emori, M. Inoue, M. Kubo, Coord. Chem. Rev. 21 (1976) 1.

[46] J.-H. Luo, M.-C. Hong, R.-H. Wang, R. Cao, L. Han, Z.-Z. Lin, Eur. J. Inorg. Chem. (2003) 2705.

[47] A. Tahri, E. Cielen, K.J.V. Aken, G.J. Hoornaert, F.C.D. Schryver, N. Boens, J. Chem. Soc., Perkin Trans. 2 (1999) 1739.

[48] A. Volger, H. Kunkely, Coord. Chem. Rev. 177 (1998) 81; R.M. Berger, D.D. Ellis, Inorg. Chim. Acta 241 (1996) 1. 